\title{
Effects of Partial and Full Feed Restriction on the Plasma Levels of Thyroid Hormones and Testicular Activity in the Male Air-breathing Catfish, Clarias gariepinus during Different Phases of the Breeding Cycle
}

\author{
P Suchiang \\ Environmental Endocrinology Laboratory \\ Department of Zoology, North-Eastern Hill University \\ Shillong - 793022, Meghalaya, India \\ Present Address: Department of Zoology, Tura Govt. College \\ Tura - 794001, Meghalaya, India \\ E-Mail: pfmsng@gmail.com \\ B B P Gupta \\ Environmental Endocrinology Laboratory \\ Department of Zoology North-Eastern Hill University \\ Shillong - 793022, Meghalaya, India
}

Received: December 13, 2010 Accepted: December 28, 2010 doi:10.5539/ijb.v3n2p32

\begin{abstract}
The effects of partial and full feed restriction on the plasma levels of thyroxine $\left(\mathrm{T}_{4}\right)$, triiodothyronine $\left(\mathrm{T}_{3}\right)$ and testicular activity were studied in the male air-breathing catfish, Clarias gariepinus. Partial and full feed restriction for 3 weeks significantly decreased the plasma $\mathrm{T}_{4}$ levels during the progressive and breeding phases, and decreased the plasma $\mathrm{T}_{3}$ levels only during the breeding phase. However, full feed restriction for 3 weeks increased plasma $T_{3}$ levels and $T_{3} / T_{4}$ ratio during the quiescent, progressive and regressive phases. Histologically, 3 weeks of partial and full feed restriction markedly reduced the testicular activity during the progressive and breeding phases. These results indicate that partial and full feed restriction adversely affects the thyroid hormonogenesis and testicular activity in a phase-dependent manner in C. gariepinus.
\end{abstract}

Keywords: Thyroid hormone, Thyroxine, Triiodothyronine, Clarias gariepinus, Partial feed restriction, Full feed restriction, Testicular activity, Breeding cycle

\section{Introduction}

Thyroid hormones represent a good candidate signal in the adaptive metabolic response to starvation (Eales, 1988; De Pedro et al., 2003). Fasting and refeeding have been reported to have marked effects on the thyroid activity, circulating levels of the thyroid hormones and their metabolism in different groups of vertebrates (Eales, 1988; Wu, 1990; Cokelaere et al., 1996; Van der Geyten et al., 1999; Wright, Proctor and Alves, 1999; Kohel et al., 2001; Ortiz et al., 2001; Reyns et al., 2002; Coppola et al., 2005). In fishes, food deprivation suppresses the plasma $\mathrm{T}_{4}$ and $\mathrm{T}_{3}$ levels, reduces thyroid tissue sensitivity to thyroid stimulating hormone (TSH), causes a reduction in 5'-monodeiodinase and eliminates the plasma thyroid hormone daily patterns (Eales et al., 1981; Flood and Eales, 1983; Shields and Eales, 1986; Fabridge and Leatherland, 1992; Cerda-Reverter et al., 1996; Power et al., 2000; Gaylord et al., 2001). Besides thyroid hormones, starvation has also been reported to affect reproductive function in different fish species (Silverstein and Shimma, 1994; Karlsen et al., 1995; Collins and Anderson, 1999; Duston and Saunders, 1999; Frantzen et al., 2004). However, these reports on the effects of feed restriction on the thyroid hormones and gonadal activity are limited to only a few temperate zone fish species and without any reference to the phases of the annual breeding cycle when the studies were conducted. 
Since, under natural conditions the fish physiology changes with the phase of the breeding cycle, there is a possibility that the effects of feed restriction on the levels of thyroid hormones and gonadal activity may vary with the phases of the annual breeding cycle of the fish. Therefore, more information is needed in order to evaluate the effects of feed restriction on the circulating levels of thyroid hormones and testicular activity at different phases of the fish breeding cycle. Thus, in this study in a tropical/subtropical region we have determined whether feed restriction affects the plasma levels of thyroid hormones and testicular activity in a phase-dependent manner in the male African catfish, Clarias gariepinus.

\section{Materials and Methods}

\subsection{Fish, experimental design and sampling}

All experiments were conducted on the adult male, Clarias gariepinus that breed in India during monsoon, and live in shallow rivers, ponds and muddy places. C. gariepinus can survive in low water levels with little oxygen. Specimens (body weight: 90-100 g; body length: 23-27 cm) were purchased from the local fish suppliers. Fish were maintained in clear plastic tubs and acclimatized at least for 15 days in the laboratory under natural climatic conditions at Shillong $\left(25^{\circ} .30^{\prime} \mathrm{N}, 91^{\circ} .52^{\prime} \mathrm{E}\right.$; 1450 above sea level; minimum water temperature varied from $4-6^{\circ}$ $\mathrm{C}$; maximum water temperature varied from $23-25^{\circ} \mathrm{C}$ ). During acclimatization, the fish were fed daily ad libitum with minced earthworms and commercial fish feed (Tokyu). The water was changed every day. The experiments were conducted during the quiescent, progressive, breeding and regressive phases of the annual breeding cycle of C. gariepinus.

After acclimatization, the fish were divided into three groups. The fish of the first group (control group) were fed ad libitum. The fish of the second group (partial feed restriction group) were fed on every third day for 3 weeks, while the fish of the third group (full feed restriction group) were deprived of food for 3 weeks. At the end of the experiment, four fish from each group were removed by hand net and weighed. Blood samples were collected from the post-caudal region in numbered heparinised centrifuge tubes. After blood sampling, testes were removed, weighed and fixed in the Bouin's fluid for histological study. Body and testes mass of each fish were used for calculating the gonadosomatic index (gonad mass x 100/total body mass). For obtaining plasma, blood samples were centrifuged at $3000 \mathrm{~g}$ (REMI: Model R23), plasma separated and stored at $-10{ }^{\circ} \mathrm{C}$ in a refrigerator for the measurement of $\mathrm{T}_{4}$ and $\mathrm{T}_{3}$ concentrations.

\subsection{Measurement of plasma levels of thyroxine $\left(T_{4}\right)$ and triidothyronine $\left(T_{3}\right)$}

The plasma levels of total $\mathrm{T}_{4}$ and total $\mathrm{T}_{3}$ were measured with the help of radioimmunoassay kits RIAK5/5A for $\mathrm{T}_{4}$ (sensitivity $0.625 \mathrm{ng} / \mathrm{ml}$ based on $93.67 \%$ B/Bo intercept) and RIAK4/4A for $\mathrm{T}_{3}$ (sensitivity $0.0375 \mathrm{ng} / \mathrm{ml}$ based on $90.77 \% \quad B / B o$ intercept). Radioimmunoassay kits were obtained from the Division of Radiopharmaceutical Operations, Board of Radiation and Isotope Technology (BRIT), Mumbai. The RIA of $\mathrm{T}_{4}$ and $\mathrm{T}_{3}$ were conducted following the manufacturer's protocols with slight modifications where the hormone free serum was replaced by the hormone-free fish plasma (Gupta and Premabati, 2002). RIA was validated using hormone free fish plasma and different concentrations of standard solutions of the $\mathrm{T}_{3}$ (range: $0.0375-2.4 \mathrm{ng} / \mathrm{ml}$ ) and $\mathrm{T}_{4}$ (range: $0.625-20 \mathrm{ng} / \mathrm{ml}$ ). The hormone free fish plasma used in the assay was prepared by two cycles of addition of Dextran-coated charcoal to pooled fish plasma, continuous stirring for 6 hours and centrifugation. Polyethylene glycol (PEG) solutions (12\% for $\mathrm{T}_{3}$ and $22 \%$ for $\left.\mathrm{T}_{4}\right)$ were used to separate the bound and free fractions of the $\mathrm{T}_{4}$ and $\mathrm{T}_{3}$ in the respective RIA. The intra- and inter-assay variations in the assays were found to be on average less than $3.5 \%$ and $6.5 \%$ for the $\mathrm{T}_{3}$ and $\mathrm{T}_{4}$, respectively. The radioactivity in the bound fraction was counted with the help of a well-type gamma counter (Electronic Corporation of India, Hyderabad). The concentrations of the total $\mathrm{T}_{4}$ and total $\mathrm{T}_{3}$ were expressed as $\mathrm{ng} / \mathrm{ml}$ of plasma.

\subsection{Histological study of testes}

After the testes had been in the fixative for 24-48 hours, they were removed from the fixative and were washed for 24 hours with running water. This was followed by a dehydration period of 20 minutes in each of $30 \%, 50 \%$, $70 \%, 90 \%$, and $90 \%$ and twice in a $100 \%$ ethanol range. After the dehydration process, the tissue was cleared in xylene and then embedded in paraffin wax. The hardened blocks were trimmed, mounted on tissue chucks and sectioned on a microtome into $6 \mu \mathrm{m}$ sections. Selected sections were mounted on clean glass slides, floated and stretched on a hot-plate and placed on a warming tray to dry and adhere. After dewaxing in xylene, the sections were hydrated in decreasing grades of ethanol and then stained with hematoxylin. After washing excess of hematoxylin, the sections were dehydrated in increasing grades of ethanol and stained with eosin. The stained sections were then further dehydrated, cleared in xylene and mounted with cover slips using DPX. The sections were examined under Zeiss Microscope and photographed. 


\subsection{Statistical analyses}

The data were statistically analyzed with the help of analysis of variance (ANOVA). A probability of $\mathrm{P}<0.05$ was considered as significant.

\section{Results}

\subsection{Effects of partial feed restriction on the plasma levels of thyroid hormones}

Partial feed restriction for 3 weeks significantly decreased the plasma $T_{4}$ levels during the progressive and breeding phases as compared to the ad libitum fed control group, while it had no effect on $\mathrm{T}_{4}$ levels during the quiescent and regressive phases (Figure 1). Further, partial feed restriction decreased the plasma $T_{3}$ level significantly but only during the breeding phase (Figure 2). Irrespective of the phases of the annual breeding cycle, partial feed restriction had no significant effect on the $\mathrm{T}_{3} / \mathrm{T}_{4}$ ratio (Figure 3 ).

\subsection{Effects of full feed restriction on the plasma levels of thyroid hormones}

In general, full feed restriction for 3 weeks decreased the plasma $T_{4}$ levels during all phases of the annual breeding cycle, however, as compared to that of the ad libitum fed control group significant decreases in the $\mathrm{T}_{4}$ levels were found only during the progressive and breeding phases (Figure 1). Unlike the $T_{4}$ levels, full feed restriction significantly increased the plasma $T_{3}$ levels during all the phases except during the breeding phase when it significantly decreased the plasma $T_{3}$ levels (Figure 2). Similarly, the $T_{3} / T_{4}$ ratio was found to have increased following full feed restriction during all phases of the breeding cycle; however, significant increase was found only during the quiescent, progressive and regressive phases (Figure 3).

\subsection{Effects of partial and full feed restriction on testicular histology}

Irrespective of the phases, neither partial nor full feed restriction had any significant effect on the GSI. However, in both the treated groups insignificant decreased in the GSI values were found during the progressive and breeding phases as compared to the GSI values in the control group (Figure 4). Histological observations revealed that 3 weeks of partial and full feed restriction adversely affected the testicular histology of $C$. gariepinus during certain phases of the annual breeding cycle.

During the quiescent phase (Plate 1), the seminiferous lobules of the testis in the control group were small and contained large number of spermatogonia along with small number of spermatocytes. Similarly, the seminiferous lobules in the testes of the fish on partial feed restriction group contained large number of sprematogonia and spermatocytes. Partial feed restriction had no visible effect on the seminiferous lobules. However, full feed restriction for three weeks resulted in an apparent cellular disorganization of the seminiferous lobules and the lobules contained lower number of spermatogonia as compared to that of the fish in the control group.

During the progressive phase (Plate 2), the seminiferous lobules of the testis of the fish in the control group contained almost all stages of spermatogenesis and the seminiferous lobules are much extended as compared to that of the quiescent phase. Few spermatogonia and numerous spermatocytes, spermatids as well as spermatozoa were observed in the lobules. Spermatocytes, spermatids and spermatozoa in the lobules of the partial feed restriction group are considerably decreased probably due to their degeneration. Full feed restriction resulted in an apparent cellular disorganization of the seminiferous lobules. Lobules of the testes in the full feed restriction group became smaller, but contained degenerated residual spermatozoa as well as spermatids. Spermatocytes are much reduced as compared to the control group.

During the breeding phase (Plate 3), lumens of the seminiferous lobules of the testis in the control group were filled up with large amount of matured spermatozoa. Few spermatogonia as well as spermatocytes are also visible at the periphery of the lobules. Partial feed restriction had no visible effect on the diameter of the seminiferous lobules; however, it resulted in reduction in the density of spermatozoa probably due to their degeneration. Following partial feed restriction, spermatogonia and spermatocytes lines the walls of the lobules are also visible. Full feed restriction resulted in an apparent cellular disorganization of lobules periphery producing lobules wall lined by continuous layer of degenerating spermatogonial cells. Further, degenerated residual spermatozoa remained scattered in the lumens of lobules in the full feed restriction group.

During the regressive phase (Plate 4), the diameter of the seminiferous lobules in the control fish became smaller as compared to that of the control group in the progressive and breeding phases. Further, the lobules contained degenerating spermatogonia and spermatocytes as well as residual spermatozoa indicating that the lobules of the testis are regressing. Partial and full feed restriction had no visible effects on the testicular histology as compared to that of the control group. 


\section{Discussion}

Reduced food intake or starvation is generally associated with reduced thyroid hormones concentrations in different groups of vertebrates (Oppenheimer et al., 1987; Eales, 1988; Cokelaere et al., 1996; Van der Geyten et al., 1999; Reyns et al., 2002). Since thyroid hormones are associated with an increase in metabolic rate, these hormones are usually reduced during periods of food deprivation as a means to conserve energy (Oppenheimer $e t$ al., 1987). However, in aquatic mammals, it has been reported that the concentration of thyroid hormones increased during a period of restricted food intake (Ortiz et al., 2000; Ortiz et al., 2001). As in other vertebrates, in the present study in C. gariepinus, the plasma levels of thyroid hormones were affected by both partial and full feed restriction. Three weeks of partial feed restriction was found to elicit significant decrease in the plasma levels of $T_{4}$ only during the progressive and breeding phases. Though, full feed restriction was found to significantly decrease the $T_{4}$ levels only during the progressive and breeding phases, insignificant decreased were also recorded during the quiescent and regressive phases. However, during the quiescent, progressive and regressive phases full feed restriction resulted in significant increase in the plasma levels of $\mathrm{T}_{3}$. Feed restriction has been reported to decrease both the $\mathrm{T}_{4}$ and $\mathrm{T}_{3}$ levels in temperate zone fishes like trout (Flood and Eales, 1983; Fabridge et al., 1992; Leatherland and Farbridge, 1992; Raine et al., 2005), sea bass (Cerda-Reverter et al., 1996); sea bream (Power et al., 2000) and tench (De Pedro et al., 2003). However, in the present study, partial and full feed restrictions were found to decrease both the $\mathrm{T}_{4}$ and $\mathrm{T}_{3}$ levels only during the breeding phase. It, thus, seems that feeding status (partial or full feed restriction) affects the plasma levels of thyroid hormones in a phase-dependent manner. Fasting has also been reported to alter the activity of deiodinase enzymes in vertebrates (Shields and Eales, 1986; Wu, 1990; Diano et al., 1998; Van der Geyten et al., 1998) and so, the increase in the $\mathrm{T}_{3} / \mathrm{T}_{4}$ ratio in the present study suggest increased deiodination in this fish during the full feed restriction period. Further, in vertebrates, fasting has been shown to down-regulate the hypothalamo-hypophyseal-thyroidal (HHT) axis which is assumed to represent an energy-saving mechanism in times of food shortage (van Haasteren et al., 1996; Boelen et al., 2008). Therefore, the observed changes in the plasma levels of thyroid hormones following 3 weeks of restriction to food intake might also be related to the alteration in the HHT axis of $C$. gariepinus. But at what level of the brain-pituitary-thyroid axis changes during feed restriction affect the plasma levels of thyroid hormones in C. gariepinus remains to be investigated. Thus, present findings seem to suggest that as compared to the phase-dependent differential and adverse effects of partial feed restriction on the circulating levels of $\mathrm{T}_{4}$ and $\mathrm{T}_{3}$, full feed deprivation produced a more pronounced inhibitory effect on the synthesis of $\mathrm{T}_{4}$ (as indicated by the decreased $T_{4}$ levels) and stimulatory effect on deiodination of $T_{4}$ to $T_{3}$ (as indicated by the increased $T_{3} / T_{4}$ ratio). It, thus, seems that both restricted availability and absence of food differentially affect the levels of $\mathrm{T}_{4}$ and $\mathrm{T}_{3}$ in a phase-dependent manner in C. gariepinus. While decreased thyroid hormonogenesis might be an adaptative mechanism to conserve energy when food is scarce, enhanced conversion of $T_{4}$ to $T_{3}$ (as indicated by the increased $T_{3} / T_{4}$ ratio) seems to be an adaptive mechanism to maintain an optimal level of metabolic rate essential for the survival of the fish facing food scarcity.

While there is a general awareness on the effects of fasting/starvation on fecundity, GSI, sexual maturation and temporal changes in the plasma concentrations of sex steroids in several temperate zone fish species like Amago salmon (Oncorhynchus masou ishikawae), Atlantic cod (Gadus morhua), perch (Macquaria ambigua), Atlantic salmon (Salmo salar), and Arctic charr, Salvelinus alpinus (Silverstein and Shimma, 1994; Karlsen et al., 1995; Collins and Anderson, 1999; Duston and Saunders, 1999; Frantzen et al., 2004), there is scarcity of information on the effects of partial and full feed restriction on the testicular activity of fish species in tropical/sub-tropical region with particular reference to different phases of the annual breeding cycle.

In the present study, testicular histology revealed that partial and full feed restriction had prominent adverse effects on testicular activity in C. gariepinus. Partial feed restriction and absence of food for 3 weeks adversely affect/reduce the testicular activity in terms of spermatogenesis during the progressive and breeding phases. Little change in the testicular histology was also found in the testes of the fish in full feed restriction group during the quiescent phase. However, the results of the experiment during the progressive and breeding phases clearly indicate that nutritional deficiency or scarcity of food strongly interfere with the reproductive function in the fish. It is well known that in fishes, reproductive function is mainly regulated by the hypothalamo-hypophyseal-gonadal (HHG) axis (Francis et al., 1993; Weltzien et al., 2004). Moreover, the testes/or spermatogenesis are mainly regulated by the gonadotrophins via acting through the intermediate 11-ketotestosterone as well as testosterone secreted by the Leydig cells (Miura et al., 1991; Nagahama et al., 1994; Cavaco et al., 2001), and starvation has been reported to impair reproductive functions through alterations in the HHG axis in higher vertebrates (Jorgensen, 1982; Temple and Rissman, 2000; Compagnuccia et al., 2003). Therefore, there is a strong possibility that the observed distinct and prominent regression in the testicular 
activity following three weeks of partial and full feed restriction during the progressive and breeding phases of the annual breeding cycle might be related to the impairment of the functions of the HHG axis of C. gariepinus. Thus, it may be suggested that the HHG axis in C. gariepinus may become more sensitive to the adverse effects of food scarcity during the progressive and breeding phases of the annual breeding cycle to ensure that spermatogenesis occurs only when there is no scarcity of food. However, at what level of the HHG axis is affected by partial and full feed restriction in C. gariepinus remains to be investigated. As stated earlier, 11-ketotestosterone and testosterone are involved in the regulation of spermatogenesis in fishes, it may also be suggested that the observed changes in the testicular histology following partial and full feed deprivation might be related to the decreased in the male sex steroids and need to be studied in the fish. Further, it is now well established that thyroid hormones influence reproductive function at various levels of gonadal cell differentiation and steroidogenesis, and modulate the HHG axis in fishes (Tagawa et al., 1994; Timmermans et al., 1997; Volkoff et al., 1999; Blanton and Specker, 2007; Swapna and Senthilkumaran, 2007). Therefore, based on the present findings on effects of partial and full feed restriction on the plasma levels of thyroid hormones and testicular activity, it may be further suggested that food scarcity inhibits the process of spermatogenesis probably by suppressing the HHG axis as well as the HHT axis in C. gariepinus. It is important to mention that in the previous studies on the effects of fasting/starvation on the levels of thyroid hormones and gonadal activity in temperate zone fish species the experiments were not conducted during different phases of the annual breeding cycle. Moreover, simultaneous observations were not made on the levels of thyroid hormones and testicular/gonadal activity. However, present findings when taken together with the earlier reports strongly suggest that partial and full feed restriction differently affects the plasma levels of the thyroid hormones and testicular activity in a tropical/subtropical and temperate zone fish species, which might have evolved different mechanisms to adapt against food scarcity.

\section{Conclusion}

The present study seems to be the first of its kind in which the plasma levels of thyroid hormones and testicular activity have been studied simultaneously in a fish maintained under partial and full feed restriction during all major phases of the annual breeding cycle. Our findings, may explain, in part, the phase-dependent effects of feeding status on the circulating levels of thyroid hormones and testicular activity in C. gariepinus. It may be suggested that partial and full feed restriction adversely affect the thyroid hormonogenesis as indicated by the decreased plasma levels of $\mathrm{T}_{4}$ in $C$. gariepinus. Further, it may also be suggested that food scarcity inhibits the process of spermatogenesis probably by suppressing the HHG axis as well as the HHT axis to avoid breeding during a period when food availability is meager. Thus, the results of this study indicate that under practical conditions, Clarias gariepinus should be fed daily as even three weeks of partial and full feed deprivation adversely affect the thyroid hormonogenesis and testicular activity of the fish.

\section{Acknowledgements}

Financial assistance in the form of Rajiv Gandhi National Fellowship from the Ministry of Tribal Affairs, Government of India is gratefully acknowledged.

\section{References}

Blanton, M.L., \& Specker, J.L. (2007). The hypothalamic-pituitary-thyroid (HPT) axis in fish and its role in fish development and reproduction. Critical Review of Toxicology, 37, 97-115.

Boelen, A., Wiersinga, W.M., \& Fliers, E. (2008). Fasting-induced changes in the hypothalamus-pituitary-thyroid axis. Thyroid, 18, 123-120.

Cavaco, J.E., Bogerd, J., Goos, H., \& Schulz, R.W. (2001). Testosterone Inhibits 11-Ketotestosterone-Induced Spermatogenesis in African Catfish (Clarias gariepinus). Biology of Reproduction, 65, 1807- 1812.

Cerda-Reverter, J. M., Zanuy. S., Carrillo, M., \& Kah, O. (1996). Development of enzyme immunoassays for 3,5,3'-triiodo-L-thyronine and L-thyroxine: time-course studies on the effect of food deprivation on plasma thyroid hormones in two marine teleosts, sea bass (Dicentrarchus labrax L.) and sea bream (Sparus aurata L.). General and Comparative Endocrinology, 103, 290-300.

Cokelaere, M., Decuypere, E., Flo, G., Darras, V. M., \& Kuhn, E. R. (1996). Influence of feeding pattern on thyroid hormones in long-term food restricted rats. Hormone and Metabolism Research, 28, 315-318.

Collins, A. L., \& Anderson, T. A. (1999). The role of food availability in regulating reproductive development in female golden perch. Journal of Fish Biology, 55, 94-104.

Compagnuccia, C. V., Compagnucci, G. E., Lomniczi, A., Mohn, C., Vacas, I., Cebral, E., Elverdin, J. C., 
Friedman, S. M., Rettori, V., \& Boyer, P. M. (2003). Effect of nutritional stress on the hypothalamo-pituitary-gonadal axis in the growing male rat. Neuroimmunomodulation, 10, 153-162.

Coppola, A., Meli, R., \& Diano, S. (2005). Inverse shift in circulating corticosterone and leptin levels elevates hypothalamic deiodinase type 2 in fasted rats. Endocrinology, 146, 2827-2833.

De Pedro, N., Delgado, M. J., Gancedo, B., \& Alonso-Bedate, M. (2003). Changes in glucose, glycogen, thyroid activity and hypothalamic catecholamines in tench by starvation and refeeding. Journal of Comparative Physiology B, 173, 475-481.

Diano, S., Naftolin, F., Goglia, F., \& Horvath, T. L. (1998). Fasting-induced increase in type II iodothyronine deiodinase activity and messenger ribonucleic acid levels is not reversed by thyroxine in the rat hypothalamus. Endocrinology, 139, 2879-2884.

Duston, J., \& Saunders, R. L. (1999). Effect of winter food deprivation on growth and sexual maturity of Atlantic salmon (Salmo salar) in sea water. Canadian Journal of Aquatic Science, 56, 201-207.

Eales, J. G. (1988). The influence of nutritional state on thyroid function in various vertabrates. American Zoologist, 28, 351-362.

Eales, J. G., Hughes, M., \& Uin, L. (1981). Effect of food intake on diel variation in plasma thyroid hormone levels in rainbow trout, Salmo gairdneri. General and Comparative Endocrinology, 45, 167-174.

Fabridge, K. J., \& Leatherland, J. F. (1992). Temporal change in plasma thyroid hormone, growth hormone and free fatty acid concentrations, and hepatic 5'-monodeiodinase activity, lipid and protein content during chronic fasting and re-feding in rainbow trout (Oncorhynchus mykiss). Fish Physiology and Biochemistry, 10, $245-257$.

Fabridge, K. J., Flett, P. A., \& Leatherland, J. F. (1992). Temporal effects of restricted diet and compensatory increased dietary intake on thyroid function, plasma growth hormone levels and tissue lipid reserves in rainbow trout, Oncorhynchus mykiss. Aquaculture, 104, 157-174.

Flood, C. G., \& Eales, J. G. (1983). Effects of starvation and refeeding on plasma $\mathrm{T}_{4}$ and $\mathrm{T}_{3}$ levels and $\mathrm{T}_{4}$ deiodination in rainbow trout, Salmo gairdneri. Canadian Journal of Zoologist, 61, 1949-1953.

Francis, R. C., Soma, K., \& Fernald, R. D. (1993). Social regulation of the brain-pituitary-gonadal axis. Proceedings of National Academy of Science, USA, 90, 7794-7798.

Frantzen, M., Damsgard, B., Tveiten, H., Moriyama, S., Iwata, M., \& Johnsen, H. K. (2004). Effects of fasting on temporal changes in plasma concentrations of sex steroids, growth hormone and insulin-like growth factor I, and reproductive investment in Arctic charr. Journal of Fish Biology, 65, 1526-1542.

Gaylord, T. G., Mackenzie, D. S., \& Gatlin, D. M. (2001). Growth performance, body composition and plasma thyroid hormones status of channel catfish (Ictalurus punctuta) in response to short-term food deprivation and refeeding. Fish Physiology and Biochemistry, 24, 73-79.

Gupta, B. B. P., \& Premabati, Y. (2002). Differential effects of melatonin on plasma levels of thyroxine and triiodothyronine levels in the air-breathing fish, Clarias gariepinus during breeding and quiescent periods. General and Comparative Endocrinology, 129, 146-151.

Jorgensen, C. B. (1982). Factors controlling the ovarian cycle in a temperate zone anuran, the toad Bufo bufo: food uptake, nutritional state, and gonadotropin. Journal of Experimental Zoology, 224, 437-443.

Karlsen, O., Holm, J. C., \& Kjesbu, O. S. (1995). Effects of periodic starvation on reproductive investment in first-time spawning Atlantic cod (Gadus morhua L.). Aquaculture, 133, 159-170.

Kohel, K. A., MacKenzie, D. S., Rostal, D. C., Grumbles, J. S., \& Lance, V. A. (2001). Seasonality in plasma thyroxine in the desert tortoise, Gopherus agassizii. General and Comparative Endocrinology, 121, $214-222$.

Leatherland, J. F., \& Farbridge,. K. J. (1992). Chronic fasting reduces the response of the thyroid to growth hormone and $\mathrm{TSH}$, and alters the growth hormone related changes in hepatic 5'-monodeiodinase activity in Rainbow trout, Oncorynchus mykiss. General and Comparative Endocrinology, 87, 342-353.

Miura, T., Yamauchi, K., Takahashi, H., \& Nagahama, Y. (1991). Hormonal induction of all stages of spermatogenesis in vitro in the male Japanese eel (Anguilla japonica). Proceedings of National Academy of Science USA, 88, 5774-5778.

Nagahama, Y., Miura, T., \& Kobayashi, T. (1994). The onset of spermatogenesis in fish. Ciba Found Symposium, $182,255-267$.

Oppenheimer, J. H., Schwartz, H. L., Mariash, C. N., Kinlaw, W. B., Wong, N. C. W., \& Freake, H. C. (1987). 
Advances in our understanding of thyroid hormone action at the cellular level. Endocrine Review, 8, 288-308.

Ortiz, R. M., Mackenzie, D. S., \& Worthy, G. A. J. (2000). Thyroid hormone concentrations in captive and free-ranging West Indian mamatees (Trichechus manatus). Journal of Experimental Biology, 203, 3631-3637.

Ortiz, R. M., Wade, C. E., \& Ortiz, C. L. (2001). Effects of prolonged fasting on plasma cortisol and TH in postweaned Northern elephant seal pups. American Journal of Physiology, Regulatory, Integrative and Comparative Physiology, 280, R790-R795.

Power, D. M., Melo, J., \& Santos, C. R. A. (2000). The effect of food deprivation and refeeding on the liver, thyroid hormones and transthyretin in sea bream. Journal of Fish Biology, 56, 374-387.

Raine, J. C., Cameron, C., Vijayan, M. M., Mackenzie, D. S., \& Leatherland, J. F. (2005). Effect of fasting on thyroid hormone levels, and TR $\alpha$ and TR $\beta$ mRNA accumulation in late-stage embryo and juvenile Rainbow trout, Oncorynchus mykiss. Comparative Biochemistry and Physiology A, 140, 452-459.

Reyns, G. E., Janssens, K. A., Buyse, J., Kuhn, E. R., \& Darras, V. M. (2002). Changes in thyroid hormone levels in chicken liver during fasting and refeeding. Comparative Biochemistry and Physiology B, 132, 239-245.

Shields, C. A., \& Eales, J. G. (1986). Thyroxine-5'-deiodinase activity in hepatocytes of rainbow trout, Salmo gairdneri: Distribution, effects of starvation, and exogenous inhibitors. General and Comparative Endocrinology, 63, 334-343.

Silverstein, J. T., \& Shimma, H. (1994). Effect of restricted feeding on early maturation in female and male Amago salmon (Oncorhynchus masou ishikawae). Journal of Fish Biology, 45, 1133-1135.

Swapna, I., \& Senthilkumaran, B. (2007). Thyroid hormones modulate the hypothalamo-hypophyseal-gonadal axis in teleosts: Molecular insights. Fish Physiology and Biochemistry, 33, 335-345.

Tagawa, M., Ogasawara, T., Sakamoto, T., Miura, T., Yamauchi, K., \& Hirano, T. (1994). Thyroid hormone concentrations in the gonads of wild chum salmon during maturation. Fish Physiology and Biochemistry, 13, 233-240.

Temple, J. L., \& Rissman, E. F. (2000). Acute refeeding reverses food restriction-induced hypothalamic-pituitary-gonadal axis deficits. Biology of Reproduction, 63, 1721-1726.

Timmermans, L. P., Chmilevsky, D. A., Komen, H., \& Schipper, H. (1997). Precocious onset of spermatogenesis in juvenile carp (Cyprinus carpio L., Teleostei) following treatment with low doses of L-thyroxine. European Journal of Morphology, 35, 344-353.

Van der Geyten, S., Mol, K. A., Pluymers, W., Kuhn, E. R., \& Darras, V. M. (1998). Changes in plasma $T_{3}$ during fasting/refeeding in Tilapia (Oreochromis niloticus) are mainly regulated through changes in hepatic type II iodithyronine deiodinase. Fish Physiology and Biochemistry, 19, 135-145.

Van der Geyten, S., Van Rompaey, E., Sanders, J. P., Visser, T. J., Kuhn, E. R., \& Darras, V. M. (1999). Regulation of thyroid hormone metabolism during fasting and refeeding in chicken. General and Comparative Endocrinology, 116, 272-280.

van Haasteren, G. A., Linkels, E., van Toor, H., Klootwijk, W., Kaptein, E., de Jong, F. H., Reymond, M. J., Visser, T. J., \& de Greef, W. J. (1996). Effects of long-term food reduction on the hypothalamus-pituitary-thyroid axis in male and female rats. Journal of Endocrinology, 150, 169-178.

Volkoff, H., Wourms, J. P., Amsebury, E., \& Snelson, F. F. (1999). Structure of the thyroid gland, serum thyroid hormones, and the reproductive cycle of Atlantic Stingray, Dasyatis sabina. Journal of Experimental Zoology, 284, 505-516.

Weltzien, F. A., Andersson, E., Andersen, O., Shalchian-Tabrizi, K., \& Norberg, B. (2004). The brain-pituitary-gonad axis in male teleosts with special emphasis on Flatfish (Pleuronectiformes). Comparative Biochemistry and Physiology A, 137, 447-477.

Wright, M. L., Proctor, K. L., \& Alves, C. D. (1999). Hormonal profiles correlated with season, cold and starvation in Rana catesbeiana (bullfrog) tadpoles. Comparative Biochemistry and Physiology C, 124, 109-116.

$\mathrm{Wu}, \mathrm{S}$. Y. (1990). The effect of fasting on thyroidal $\mathrm{T}_{4}-5^{\prime}$ monodeiodinating activity in mice. Acta Endocrinologica, 122, 175-180. 


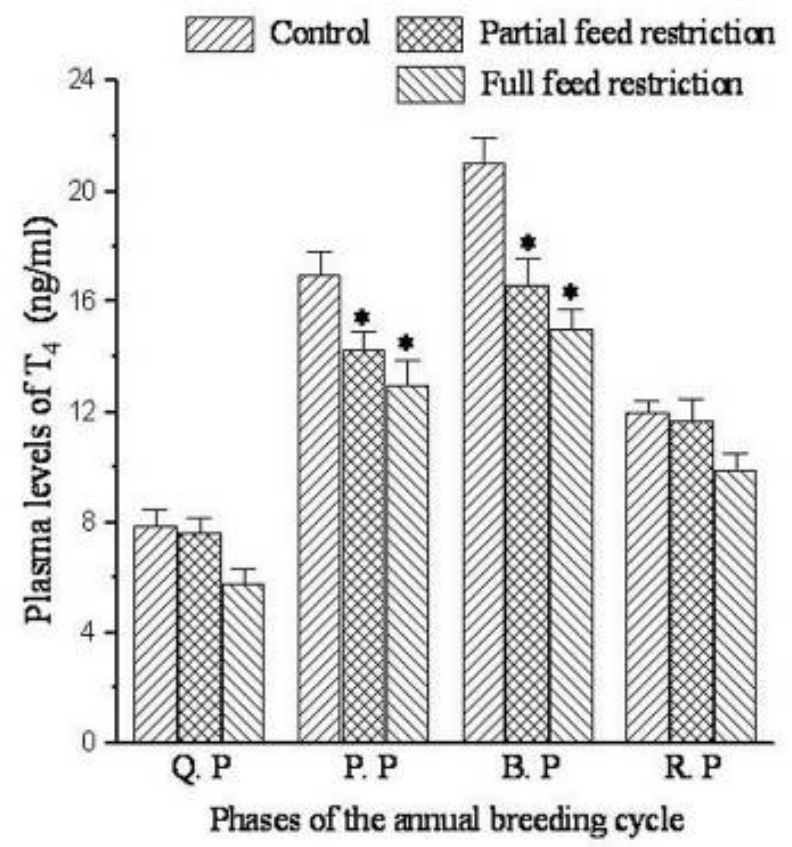

Figure 1. Changes in plasma levels of thyroxine $\left(\mathrm{T}_{4}\right)$ in male Clarias gariepinus after 3 weeks of partial and full feed restriction during different phases of the annual breeding cycle. (Q. P., Quiescent phase; P. P., Progressive phase; B. P., Breeding phase; R. P., Regressive phase).

All values are given as Mean \pm S.E.; $(n=4)$

${ }^{*}$ indicates a significant difference $(\mathrm{P}<0.05)$ to the control group.

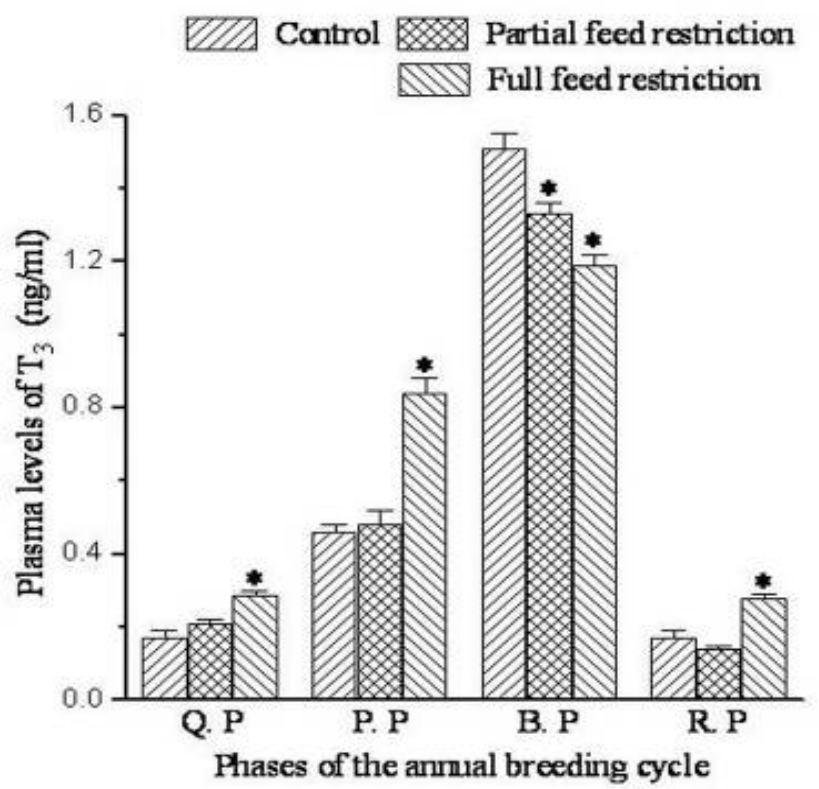

Figure 2. Changes in plasma levels of triiodothyronine $\left(\mathrm{T}_{3}\right)$ in male Clarias gariepinus after 3 weeks of partial and full feed restriction during different phases of the annual breeding cycle. (Q. P., Quiescent phase; P. P., Progressive phase; B. P., Breeding phase; R. P., Regressive phase).

All values are given as Mean \pm S.E.; $(n=4)$

${ }^{*}$ indicates a significant difference $(\mathrm{P}<0.05)$ to the control group. 


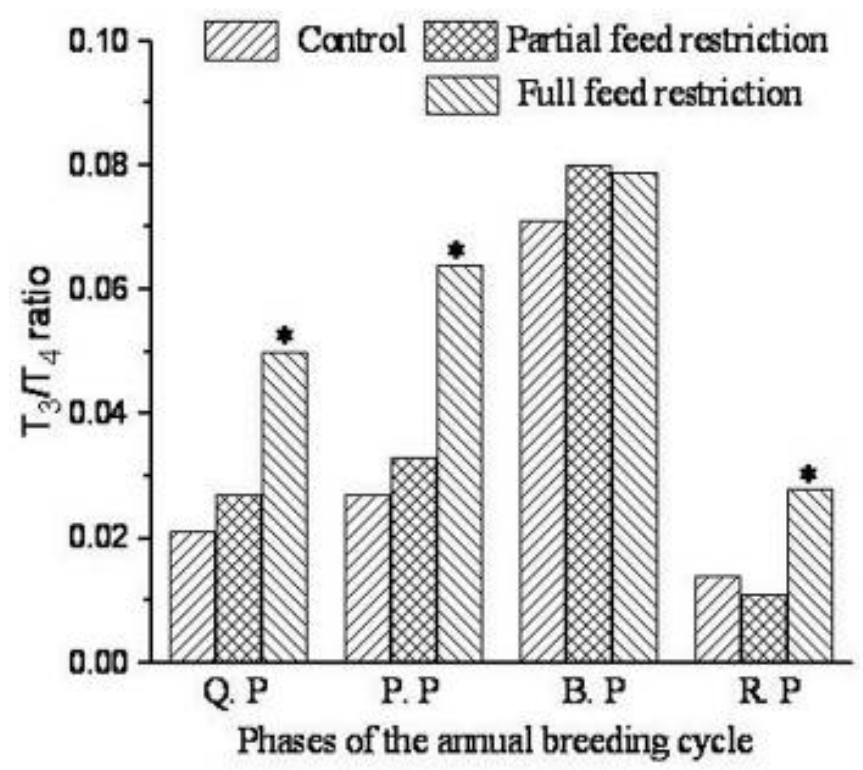

Figure 3. Changes in the $T_{3} / T_{4}$ ratio in male Clarias gariepinus after 3 weeks of partial and full feed restriction during different phases of the annual breeding cycle. (Q. P., Quiescent phase; P. P., Progressive phase; B. P., Breeding phase; R. P., Regressive phase).

${ }^{*}$ indicates a significant difference $(\mathrm{P}<0.05)$ to the control group.

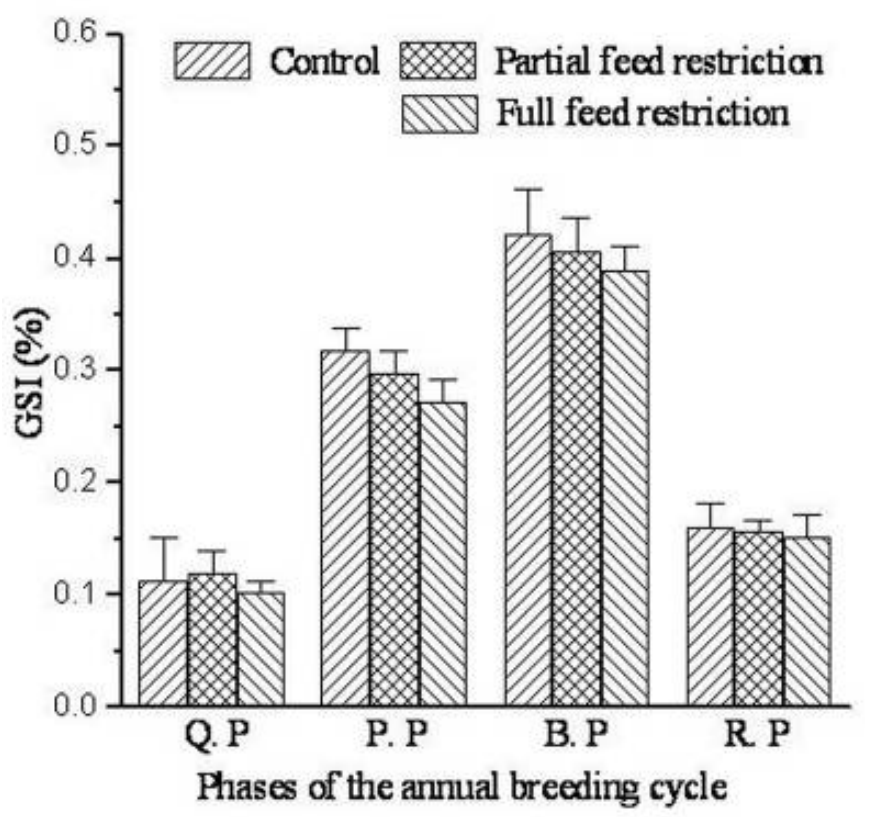

Figure 4. Changes in the gonadosomatic index (GSI) in male Clarias gariepinus after 3 weeks of partial and full feed restriction during different phases of the annual breeding cycle. (Q. P., Quiescent phase; P. P., Progressive phase; B. P., Breeding phase; R. P., Regressive phase). 


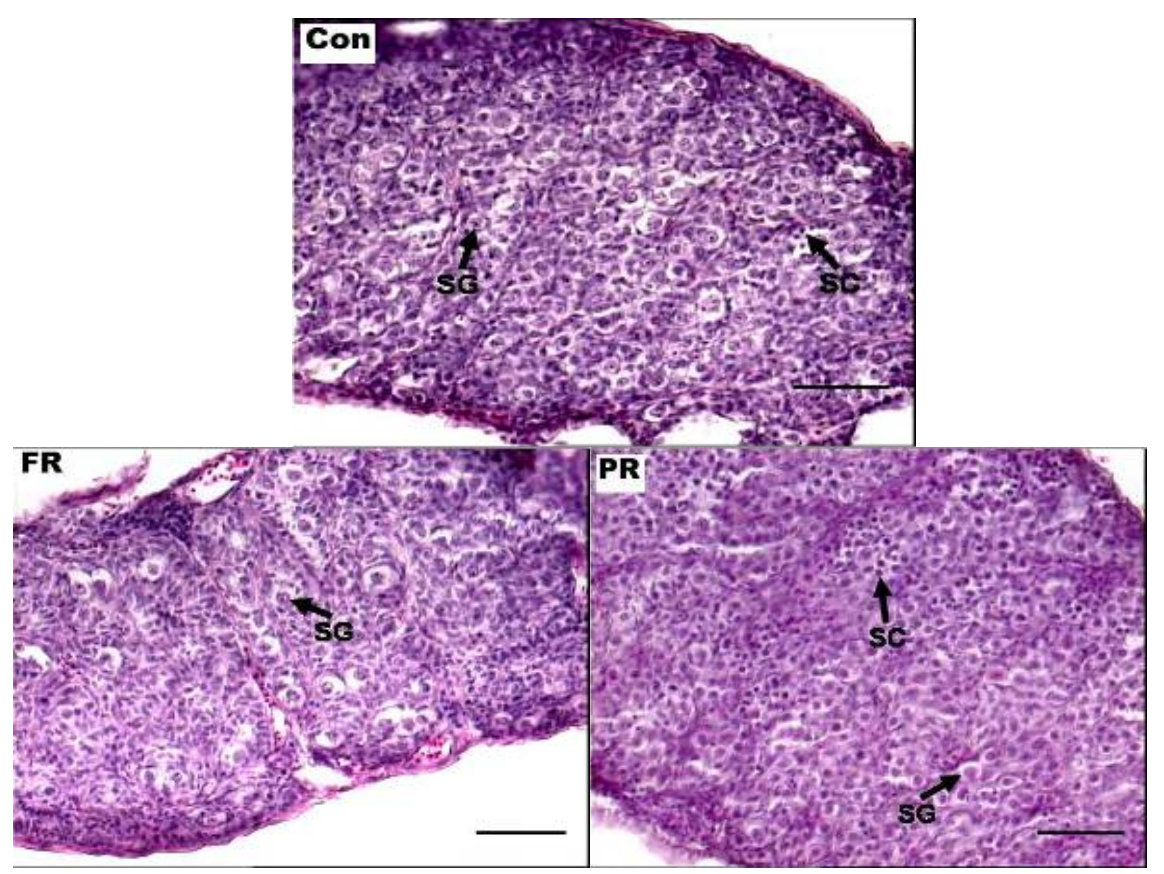

Plate 1. Effects of partial and full feed restriction on the testicular histology of Clarias gariepinus during the quiescent phase. (Con, Control; PR, Partial feed restriction and FR, Full feed restriction). SG = Spermatogonia; $\mathrm{SC}=$ Spermatocytes. Bars $=100 \mu \mathrm{m}$.

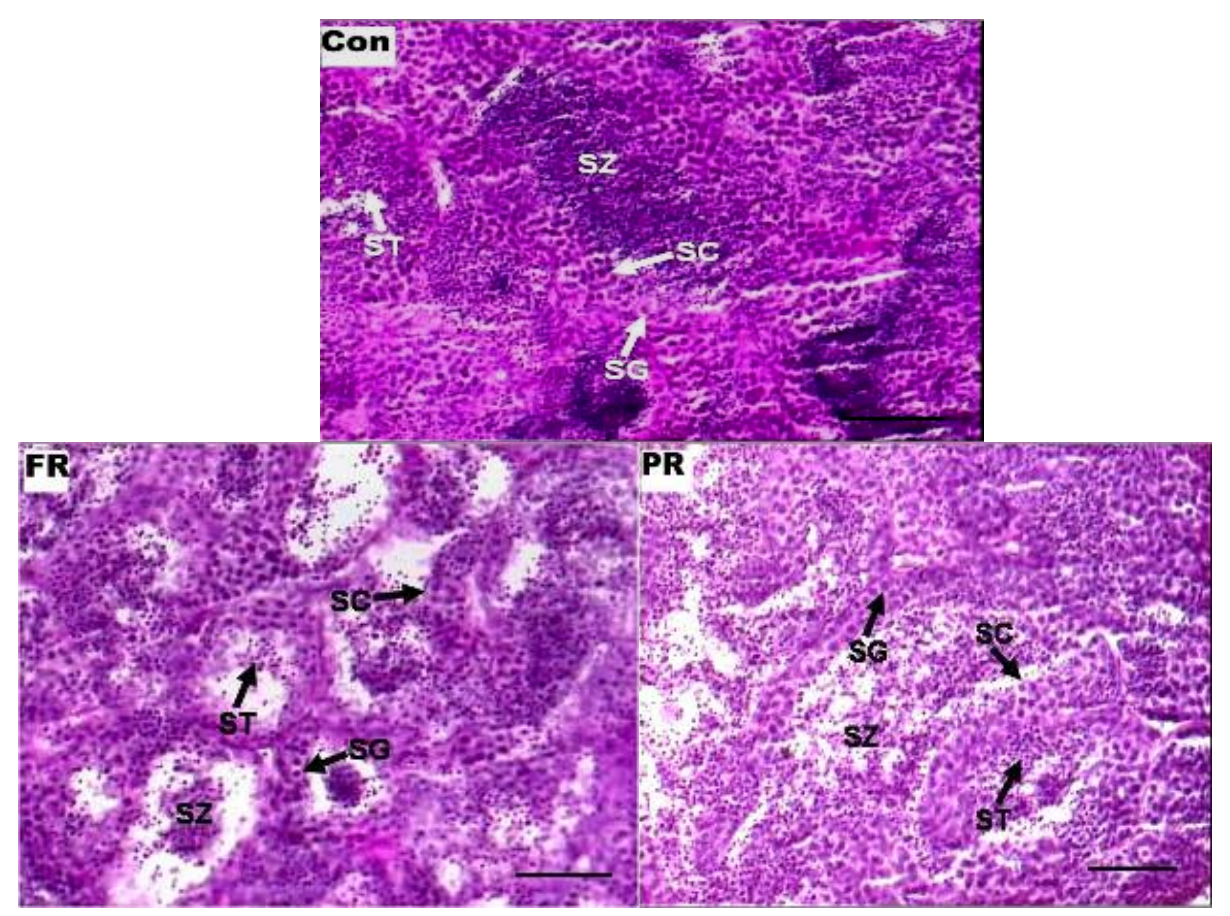

Plate 2. Effects of partial and full feed restriction on the testicular histology of Clarias gariepinus during the progressive phase. (Con, Control; PR, Partial feed restriction and FR, Full feed restriction). SG = Spermatogonia; $\mathrm{SC}=$ Spermatocytes; $\mathrm{ST}=$ Spermatids; $\mathrm{SZ}=$ Spermatozoa. Bars $=100 \mu \mathrm{m}$. 


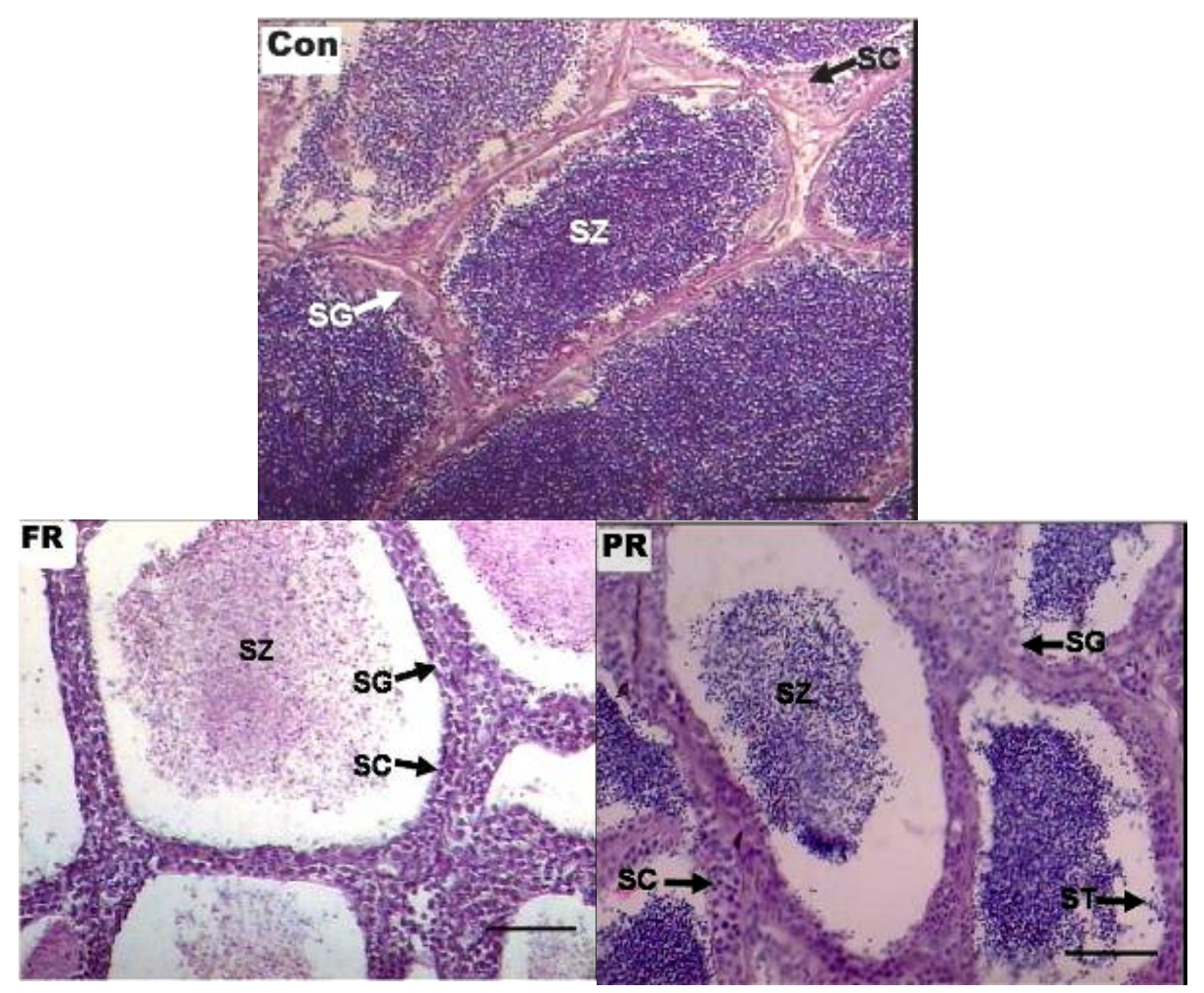

Plate 3. Effects of partial and full feed restriction on the testicular histology of Clarias gariepinus during the breeding phase. (Con, Control; PR, Partial feed restriction and FR, Full feed restriction). SG = Spermatogonia; $\mathrm{SC}=$ Spermatocytes; $\mathrm{ST}=$ Spermatids; $\mathrm{SZ}=$ Spermatozoa, Bars $=100 \mu \mathrm{m}$.

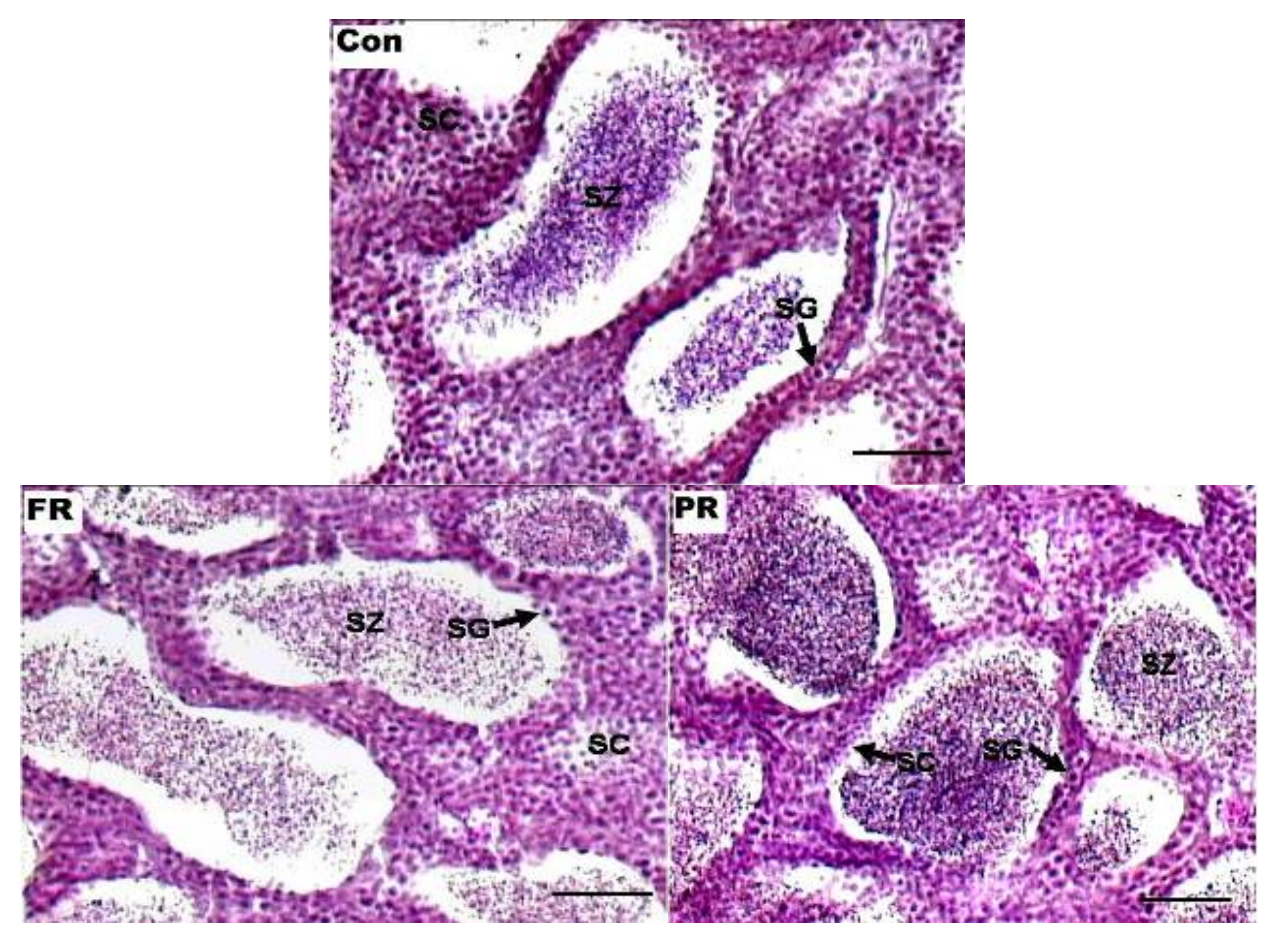

Plate 4. Effects of partial and full feed restriction on the testicular histology of Clarias gariepinus during the regressive phase. (Con, Control; PR, Partial feed restriction and FR, Full feed restriction). SG = Spermatogonia; $\mathrm{SC}=$ Spermatocytes; $\mathrm{SZ}=$ Spermatozoa. Bars $=100 \mu \mathrm{m}$ 